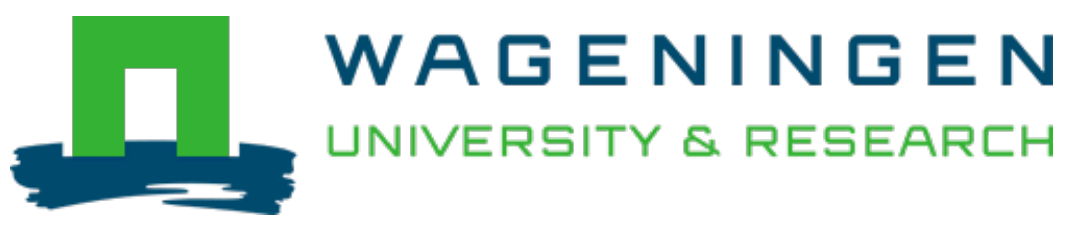

\title{
Strengthening the socio-ethical foundations of the circular economy: Lessons from responsible research and innovation
}

\author{
Journal of Cleaner Production \\ Inigo, Edurne A.; Blok, Vincent \\ https://doi.org/10.1016/j.jclepro.2019.06.053
}

This article is made publicly available in the institutional repository of Wageningen University and Research, under the terms of article $25 \mathrm{fa}$ of the Dutch Copyright Act, also known as the Amendment Taverne. This has been done with explicit consent by the author.

Article 25 fa states that the author of a short scientific work funded either wholly or partially by Dutch public funds is entitled to make that work publicly available for no consideration following a reasonable period of time after the work was first published, provided that clear reference is made to the source of the first publication of the work.

This publication is distributed under The Association of Universities in the Netherlands (VSNU) 'Article $25 \mathrm{fa}$ implementation' project. In this project research outputs of researchers employed by Dutch Universities that comply with the legal requirements of Article $25 \mathrm{fa}$ of the Dutch Copyright Act are distributed online and free of cost or other barriers in institutional repositories. Research outputs are distributed six months after their first online publication in the original published version and with proper attribution to the source of the original publication.

You are permitted to download and use the publication for personal purposes. All rights remain with the author(s) and / or copyright owner(s) of this work. Any use of the publication or parts of it other than authorised under article $25 \mathrm{fa}$ of the Dutch Copyright act is prohibited. Wageningen University \& Research and the author(s) of this publication shall not be held responsible or liable for any damages resulting from your (re)use of this publication.

For questions regarding the public availability of this article please contact openscience.library@wur.nl 


\title{
Strengthening the socio-ethical foundations of the circular economy: Lessons from responsible research and innovation
}

\author{
Edurne A. Inigo*, Vincent Blok \\ Wageningen University \& Research, Hollandseweg 1, 6706KN, Wageningen, the Netherlands
}

\section{A R T I C L E I N F O}

\section{Article history:}

Received 1 July 2018

Received in revised form

4 June 2019

Accepted 5 June 2019

Available online 5 June 2019

\section{Keywords:}

Circular economy

Responsible innovation

Sustainable development

\begin{abstract}
A B S T R A C T
The circular economy (CE) framework has captured the attention of industry and academia and received strong policy support. It is currently deemed as a powerful solution for sustainability, despite ongoing criticism on its oversimplification and lack of consideration of socio-ethical issues. In parallel, the concept of RRI has emerged strongly with a strong focus on the integration of social desirability in innovation under transparency, democracy and mutual responsiveness principles. In this paper, we critically examine the literature on the CE and RRI in order to find out how the different focus of RRI may provide an innovation governance framework to strengthen the $\mathrm{CE}$ framework. There are two main ways in which RRI could further the CE: first, anticipating unexpected consequences, helping to break disciplinary barriers and acknowledging systemic limits that are not currently taken into consideration; and second, the integration of socio-ethical issues in the $\mathrm{CE}$, and addressing the social implications of the $\mathrm{CE}$ through stakeholder participation. However, future research should look at remaining blind spots of CE and RRI, such as non-technological innovation, the demand-side of innovation and the development of business models. With that objective, we suggest a research agenda for common development of the frameworks.
\end{abstract}

() 2019 Elsevier Ltd. All rights reserved.

\section{Introduction}

In the quest for sustainable development, businesses have emerged as important players to contribute to a transition to an economic system that ensures environmental preservation and reflects societal values. With the aim of pursuing this transition, the circular economy (CE, onwards) concept has emerged strongly, building on previous concepts and integrating a wide range of practices into a single framework (Ghisellini et al., 2016; Korhonen et al., 2018a). Businesses are important actors in this transition although policy-makers (McDowall et al., 2017; Reike et al., 2018), particularly in the European Union (European Commission, 2012a) and China (Geng and Doberstein, 2008), have also backed this framework. However, the operationalisation of the CE has often been criticised as a sustainability model for its neglect of social and ethical issues, focusing on the environmental and economic pillars of sustainability (Kirchherr et al., 2017; Murray et al., 2017). In principle, the CE aims to achieve welfare-increasing, sustainable

\footnotetext{
* Corresponding author.

E-mail address: edurne.inigo@wur.nl (E.A. Inigo).
}

economic growth, hence addressing inter and intragenerational equity concerns through the preservation of natural capital, resource productivity and the removal of negative externalities (Ellen MacArthur Foundation, 2017). Nevertheless, the concept of the $C E$ is still evolving, and many conceptualisations and frameworks to implement the $\mathrm{CE}$ in practice have not considered a dimension of social justice, both at the geographic and intergenerational levels (Murray et al., 2017). As an example, while in China the CE is seen as the environmental pillar of the "harmonious society' (Naustdalslid, 2014), in the European context the CE has typically focused with creation of jobs as the major socio-economic concern (Ellen MacArthur Foundation, 2012; Sauvé et al., 2016).

Interestingly, at the time of emergence of the $\mathrm{CE}$, another framework has emerged, mostly with the support of the European Commission (European Commision, 2012): responsible research and innovation (RRI, onwards). RRI aims to tackle the 'grand challenges' of our time through innovation and pave the way for a wider system transition to sustainability (Blok and Lemmens, 2015; Lubberink et al., 2017). Unlike the CE framework, RRI has a much stronger focus on the inclusion of socio-ethical issues, aiming to reflect societal values in innovation under principles of transparency, democracy and mutual responsiveness (Von Schomberg, 
2013). Despite its recent introduction in some other regions, RRI has found conceptual and policy support mostly in Europe (Macnaghten et al., 2014).

Both the CE and RRI ultimately aim to address problems related with sustainable development through innovation, even if their focus and means are different. The CE focuses on achieving a closed-loop, material and energy balanced economy, through the application of the 3R principles - Reduce, Reuse, and Recycle. Through them, the aim is to tackle the environmental and economic dimensions of sustainability (Geissdoerfer et al., 2017; Ghisellini et al., 2016). In order to do so, new innovative concepts, technologies and actors are to be developed to address the complexity of sustainability problems (Ghisellini et al., 2016; Linder and Williander, 2017). Diversely, RRI aims to democratise the research and innovation process so that socio-ethical issues are considered and incorporated in the development of new technologies, fostering collaboration of the innovator with its stakeholders to address the grand challenges of our time (Stilgoe et al., 2013; Von Schomberg, 2013), including -but not limited to - sustainable development (Burget et al., 2017). Hence, apart from tackling outcome-related issues (that is, addressing grand challenges) it has a strong procedural aspect, proposing a democratic, transparent and inclusive innovation process.

Despite sharing some common goals, the CE and RRI have been operationalised as separate concepts in policy and practice. For instance, at the EU level, they are managed by different Directorate General (Environment and Research and Innovation, respectively), and funding for research on these frameworks is provided by different programmes. Nevertheless, the CE and RRI show some complementarities in objectives and methods. The CE concept is essentially contested (Korhonen et al., 2018b) and still in evolution, with many definitions and conceptualisations developing in parallel (Kirchherr et al., 2017; Reike et al., 2018). Because of this, the concept of the CE serves multiple roles in different spheres: from a scientific perspective, it refers to a certain arrangement of the economic system towards closed-loop material and energy flows; from a policy perspective, it is a wider programme to embark different social actors in the quest for sustainable development; from a business perspective, it has often been implemented as a tool for resource productivity. The diverse interpretations about the concept of the CE has resulted in ongoing criticism, which sometimes stem from the distinct expectations from the concept of the $\mathrm{CE}$ in different fields. A common criticism collected in the an extensive literature flourishing around the topic is the overlook of social and ethical issues in the CE conceptualisations and practices (Korhonen et al., 2018a; Murray et al., 2017; Reike et al., 2018). Therefore, exploring the concept of the CE from and RRI lens may serve two purposes; first, to open the contested understanding and social goals of the CE through the tools of RRI (Reber, 2017; Taebi et al., 2014), and, second, to address these criticisms about the socio-ethical foundations of the CE (Murray et al., 2017) with the principles at the core of RRI (Blok and Lemmens, 2015; Burget et al., 2017):we find that there are ways in which the integration of RRI principles could help to sustain the socio-ethical foundations of the $\mathrm{CE}$. Therefore, the aim of this article is to provide an understanding of the two concepts that have been previously unconnected, to consider how RRI may be productive in the development of a more socially and ethically grounded CE.

The next section presents the materials and methods, followed by Section 3, which provides more background information about the concepts of CE and RRI, as well as. Then, Section 4 provides an overview on the identified major criticisms of the $C E$ and discusses the main commonalities of the CE and RRI concepts, followed by the ways in which RRI may be helpful in addressing the major criticisms of the CE. After that, Section 5 examines the remaining blind spots. The final section closes with conclusions.

\section{Materials and methods}

In order to find out how RRI may further the development of the $\mathrm{CE}$, we conducted a narrative literature review (Bryman and Bell, 2015), following the principles of backward snowballing sampling described by Wohlin (2014). Carrying out this type of literature review was deemed most appropriate because extensive quality reviews of both concepts have been recently published in relevant peer-reviewed journals. Therefore, the aim of this manuscript is not to perform yet another review on these topics, but rather to concentrate on the criticisms to the CE in which RRI may be useful. To identify relevant literature to build on these concepts, we selected quality reviews for our initial sample of papers (summarised in Appendix 1), which was later complemented with backward (cited) and forward (citing) searches of those papers relevant to the critical research question. Some reviews were excluded from the list of key papers because they either did not conceptualise or identify major criticisms of the CE frameworks (for instance, Lewandowski et al., 2016) or because they were focused on a single industry or topic (as it was the case for the review of Lieder and Rashid, 2016, of CE practices in the manufacturing sector, or the review of CE reporting in the consumer goods sector). In the case of RRI, some reviews were excluded because they did not contribute to answering the research question (e.g. Ruggiu, 2015).

We performed two searches in the Web of Science during July 2017; the first under the terms "circular economy" and "review", and the second under the terms "responsible innovation" or "responsible research and innovation" and "review". We also conducted the same search in June 2018 to update the results. Since the first procedure to be performed on the initial sample was backward snowballing, we limited the search to the years 2014-2018, since previous relevant references would be encountered. In addition, the framework of the CE has been contested mostly from 2013 on, during the validity check phase of its conceptual development (Blomsma and Brennan, 2017; Reike et al., 2018). The selection criteria included academic papers only, although these referred to relevant grey literature that was later included in the materials; for instance, the Ellen MacArthur Foundation's reports. The key review papers that guided the selection of materials for the CE and RRI and their relevance to the research question are summarised in Appendix 1.

\section{Overview of the CE and RRI concepts and development}

\subsection{Overview of the circular economy}

The concept of a circular economy is older than this nomenclature (Reike et al., 2018; Winans et al., 2017), and builds on ideas developed in the context of ecological economics (closed-loop economic systems) (Boulding, 1966; Stahel and Reday, 1981) and industrial ecology (Frosch, 1992; Thomas, 1997). Industrial ecology is mostly concentrated on material rather than monetary flows, although competitiveness and economic growth are also relevant for the business actors involved (Esty and Porter, 1998). However, the $\mathrm{CE}$ added a stronger economic focus.

From this basis, several other schools of thought have contributed to the development of the CE (Ellen MacArthur Foundation, 2012; Geissdoerfer et al., 2017); mainly cradle-to-cradle (McDonough and Braungart, 2003) or the blue economy (Pauli, 2010), or integral supply management control. Cleaner production frameworks are a clear antecedent of the CE at the micro level, and still encompass principles applied for circular product design; mainly, input substitution and technological optimization (Sousa- 
Zomer et al., 2018). At the policy level, the CE also builds on previous frameworks, such as the integrated pollution prevention and control (IPPC), which proposed a life-cycle approach to the utilization of the best available techniques (Schoenberger, 2009).

Due to the variety of frameworks, theoretical domains and governance levels at which the $\mathrm{CE}$ has developed, it has been very differently conceptualised in different contexts, creating varied expectation (Reike et al., 2018). For instance from an industrial ecology perspective, it is focused on closing material and energy loops, at the policy level it is understood as a tool for a wider sociotechnical change towards sustainability (McDowall et al., 2017; Murray et al., 2017). However, it has emerged as a framework for sustainable development, providing not only a particular vision and outline of a sustainable economic system, but also a collection of principles, instruments and measurable goals (Blomsma and Brennan, 2017; Korhonen et al., 2018b; Murray et al., 2017b).

The CE has been interpreted differently even in the academic debate, in which the concept has been widely contested (Korhonen et al., 2018b). An analysis of 114 definitions by Kirchherr et al. (2017) showed that only certain patterns were shared among definitions. In any case, as noted by Kirchherr et al. (2017) the most prominent definition is that provided by the Ellen MacArthur Foundation (2012:7) in its influential initial report on the CE. For this reason, for the purposes of this paper, we consider this definition:

" $[\mathrm{CE}]$ an industrial system that is restorative or regenerative by intention and design. It replaces the 'end-of-life' concept with restoration, shifts towards the use of renewable energy, eliminates the use of toxic chemicals, which impair reuse, and aims for the elimination of waste through the superior design of materials, products, systems, and, within this, business models."

\subsection{Overview of responsible research and innovation}

Since the works of Joseph Schumpeter (1912), innovation has been considered a paradigm of economic progression and a tool for increasing levels of human welfare. Moreover, in recent years it has been signalled as a major instrument towards sustainable development (European Commission, 2012b; Jay and Gerand, 2015). However, this understanding of innovation assumes that it is inherently good and neglects the uncertainty of results and potential impacts that may be associated with the adoption of a certain innovation (Von Schomberg, 2013). Aiming to hedge these potential risks, RRI has emerged as 'an attempt to govern research and innovation in order to include all the stakeholders and the public in the early stages of research and development' (Burget et al., 2017, p. 9).

At its conception, RRI was centred around radically new, emerging technologies, and more specifically, those developed in publicly funded universities and basic research centres rather than businesses. The debate on new technologies with the potential to irremediably impact the environment or the course of societal development (e.g. genetically-modified organisms or nuclear energy). To that extent, RRI builds on previous tools and frameworks that aimed to address the uncertainties derived from emerging technologies and is not completely novel. The aim of providing socially desirable outcomes from emergent technologies and the little capacity to understand all the potential consequences of this types of innovation drove policy-makers introduced technology assessment methods at different levels; including for instance, parliamentary technology assessment. As noted by Genus and Iskandarova (2018, p. 2), a variety of previous practices have informed the current understanding of RRI: among others, "technology assessment (TA), science governance, risk governance, (engineering) ethics, public and stakeholder engagement, anticipation, foresight and future studies". These practices aimed to integrate the vision of stakeholders in technology development, establishing a dialogue between the civic society and the innovator. Ultimately, this would break the divide between development and control of technology through the provision of a system for early criticism (Schot and Rip, 1997). One of these practices is constructive technology assessment, which aims to evaluate and respond to the social and human implications of innovation at the development stage, rather than examining the ex post impacts (Schot and Rip, 1997). The discipline has evolved over time and several dimensions that are collected by RRI to integrate human values in design - such as its democratic and reflective nature - had been identified by constructive technology assessment (Genus, 2006).

The way in which these practices were applied were considered insufficient by policy-makers, since they were, to some extent, driven by the collective 'gut-feeling' (Zwart et al., 2014). This led governmental institutions to the development of the ELSI and ELSA programmes in the United States and the European Union, respectively. The aim of these programmes, which constitute the basis for the later development of the RRI framework (Zwart et al., 2014), is to assess the Ethical, Legal, and Societal implications of research. Therefore, researchers should examine and hedge the unintended but potential negative consequences of their research, adopting and anticipatory attitude, embracing collaboration with different societal stakeholders and researchers from other disciplines (e.g. philosophers, science communicators, or social scientists) (Zwart et al., 2014).

Building on ELSA and the idea that innovation should reflect societal values, the concept of RRI emerged strongly under the wing of the European Union (Zwart et al., 2014). RRI calls for the inclusion of stakeholders in the innovation process as anchors of socioethical values (Blok and Lemmens, 2015). Moreover, RRI aims to better its uncertainties and potential impacts of innovation, providing with the capacity to anticipate, deliberate on and respond to such uncertainties (Owen et al., 2012). European policymakers have placed significant efforts and hopes on RRI as a means to achieve the 'right' impacts from innovation (Von Schomberg, 2012), drafting several strategies to direct innovation towards the grand challenges of society, including sustainable development (Blok and Lemmens, 2015; European Commision, 2012). Hence RRI is built on an idea of research as a multi-stakeholder process, in which science, industry and society collaborate to deliver innovations that reflect societal values.

An emergent field of literature pivoting around the operationalisation of RRI has sprouted. One of the aims of this research is to define and refine what RRI involves, beyond the inclusion of stakeholders as fenders of societal values in innovation, aiming to tackle grand challenges (Von Schomberg, 2013). The main goal becomes to identify the main dimensions of RRI so that it can be introduced in research, development and innovation processes. Some of the seminal works on RRI (Owen et al., 2012; Stilgoe et al., 2013) highlight that, for innovation to be responsible, it must be governed under a democratic framework in which socio-ethical values, represented by the voices of stakeholders, are included. Von Schomberg (2013) delves into this, proposing a transparent and interactive throughput of RRI, in which societal actors are mutually responsive to each other, which should result in an acceptable, sustainable and socially desirable innovation output. This is constructed around the idea of embeddedness of innovation in society (Saille, 2015), guiding European research policy towards 'Science with and for Society' (European Commision, 2016). Therefore, principles of RRI are concerned with the input - resolving grand challenges -, throughput - transparency, participation and 
responsiveness - and output of innovation - ethical acceptability, sustainability and social desirability - of innovations (Blok and Lemmens, 2015). With this, the importance of democratic participation (science with society) and socio-ethically acceptable and desirable results (science for society) are stressed.

With the aim of providing a governance framework for responsible innovation, Stilgoe et al. (2013) provide four dimensions of RRI processes: anticipation, reflexivity, inclusion and responsiveness. The latest reflections on RRI that aim to develop the concepts and its dimensions on the grounds of the thriving literature on the topic suggest the addition of new dimensions to the framework collected by Stilgoe et al. (2013). Burget et al. (2017) propose two new dimensions to RRI: sustainability and care. Sustainability is a common theme in the RRI literature and one of the keys to understand the use of the concept by bodies like the European Commission. It is related to the tackling of 'grand challenges' necessary for RRI outlined by Von Schomberg (2013). The addition of sustainability as a dimension of RRI is also related to the engrailment of RRI in European policies and research frameworks toward sustainable development (Madelin, 2016), and the idea that innovation - and RRI in particular - can be a useful tool to address sustainability problems (Flipse et al., 2013; Voegtlin and Scherer, 2017). Care is another dimension of RRI suggested by Burget et al. (2017), related to the future-oriented ethics that are meant to deal with the uncertainties of technological innovation (Groves, 2009).

\section{Addressing the criticisms and interpretations of the CE through RRI}

\subsection{Principles of the $C E$}

The CE concentrates on addressing environmental issues while aiming at economic growth, and is conceptualised as an alternative framework to the linear economy, within which the components and materials keep their value and are recycled, remanufactured or reabsorbed by the natural environment (Geng and Doberstein, 2008). As illustrated by Andrews (2015), as the CE is distinct to the linear economy mostly because of the treatment of materials, components and products at their end-of-life: while in the CE they are processed into closed loops and become resources for future life-cycles, in the linear economy they become waste and are either incinerated or disposed of in landfills.

This is built on the idea of embeddedness of the economic system in the natural environment and the acknowledgement of the ecosystem boundaries (Boulding, 1966) and its services to the economy (Pearce and Turner, 1992). Thus, a major concern for the $\mathrm{CE}$ is not only to ensure that the idea of material and energy circularity ingrained in the whole value chain, but also that business opportunities are created (Webster, 2013). Furthermore, Lieder and Rashid (2016) suggest that the CE must be environmentally and economically regenerative: this means that, apart from closing the material and energy loops through resorting to the bioeconomy, renewable energies and the $3 R$ principles (reuse, remanufacture, recycle), the $C E$ should aim to ensure sustainable economic growth, by creating new jobs, industries and sources of wealth creation. This translates into efforts both from the policy (through societal action, legislation and policies) and industry (ensuring profitability, competitiveness and involvement of manufacturing industries) perspectives. The majority of conceptualisations of the $\mathrm{CE}$ focus on the creation of a balance between the environmental and economic pillars of sustainable development (Ghisellini et al., 2016; Greyson, 2007), looking at social aspects only when it comes to its potential for jobs creation (Lacy and Rutqvist, 2016; Stahel, 2016). However, in the high-level policy in
China, the $\mathrm{CE}$ is planned as the environmental pillar of the harmonious society (Geng and Doberstein, 2008), the socioeconomic vision of sustainable development for China that includes green economic growth, respect among economic actors, the increase of affluence, and improvements in morals and the rule of law. However, in practice it has been mostly oriented to tackling the resource intensity of the national economy (Gregson et al., 2015; McDowall et al., 2017).

The main principles for the implementation of the $\mathrm{CE}$ are Reduction, Reuse and Recycle - 3R- (Ghisellini et al., 2016; Murray et al., 2017). It is notable that the focus of attention in each of the principles has been different depending on the geographical area (McDowall et al., 2017). Due to concerns of resource scarcity for industrial production, Reduction has become a major objective in China (Mathews and Tan, 2011), eco-efficiency indicators being very relevant for national assessment of the state of the CE (Geng et al., 2012). However, European policies have been directed mostly towards Recycle as a form of waste management and development of upcycling based industries (Gregson et al., 2015), and focusing on the minimisation of waste as an externality (Andersen, 2007). However, recycling is the least environmentally advisable of the three principles of $\mathrm{CE}$, due to energy dissipation and gradual downgrading of certain materials (Bilitewski, 2012; Stahel, 2013). Therefore, in order to achieve environmental, social and economic sustainability, it is necessary to balance the three principles and understand the CE from a systemic perspective rather than individual practices under the 3R principles (Webster, 2013).

Reduction is related to eco-efficiency; that is, the minimisation of natural resources in the form of raw materials or energy into the production process. Eco-efficiency mostly disregards the social dimension of sustainability, focusing on the natural environment as a finite provider of energy and raw materials and recipient of harmful waste to a limited carrying capacity, decoupling business activity from environmental degradation (Figge et al., 2014). Ecoefficiency has been criticised for its limited goals. Moreover, the concept of decoupling (environmental degradation from economic growth) is perilous as it suggests that the economy may function without inputs from the ecosystem (Hukkinen, 2001), and neglects functioning rules of ecosystems that may put them at risk, since the loss of spare capacity, diversity and flexibility may negatively affect long-term sustainability (Korhonen and Seager, 2008). In any case, the most highlighted issue regarding eco-efficiency is the Jevons paradox, whereby increases in efficiency increment consumption; therefore resulting in further resource scarcity (Alcott, 2005; Korhonen et al., 2018a; Korhonen and Seager, 2008).

The second principle of the CE is Reuse, which also refers to refurbishing or manufacturing; that is, extending the life of either whole products or their components for the same purpose for which they were created (European Union, 2008). Reuse is the most important strategy of the three principles of the circular economy (Castellani et al., 2015), involving less labour, energy and material (Ghisellini et al., 2016). Along with Reuse, extending the life of products is an important strategy for the CE (Cooper, 2016). However, consumer attitudes towards fashion and utility of products as well as reticence towards refurbished or remanufactured products (Baxter et al., 2017) may discourage producers from engaging in Reuse beyond legally-established obligations (Sakai et al., 2011). When it comes to reuse, a main criticism to the $C E$ is that, despite it being the most environmentally effective principle of the $3 \mathrm{R}$, policies have been mostly oriented towards eco-efficiency and recycling (McDowall et al., 2017; Sakai et al., 2011). This is so because they sustain better the economic pillar of CE, by increasing efficiency gains for producers and creating new waste-based industries, respectively. However, consumers often assign a lower 
value to reused, refurbished and remanufactured products (Baxter et al., 2017); therefore, their commercialisation would require a change in consumer attitudes. In the case of product-service systems, the value that consumers assign to ownership and control of products has hindered further application beyond the B2B sector (Tukker, 2015). Although consumer perceptions of reused products seem to be evolving towards greater acceptance (Castellani et al., 2015), this is mostly based on a thrift culture that enables further consumption, rather than on the idea of preventing waste (Gregson et al., 2013).

Finally, the Recycle principle refers to the reprocessing of waste materials for the same or different uses than those that they were originally used for (European Union, 2008). Recycling reduces the amount of waste that needs to be burned or buried on landfills; and it is also a useful strategy to avoid sourcing materials from the natural environment (Geng and Doberstein, 2008). However, certain materials cannot be recycled indefinitely, since the material is downgraded after a certain number of re-processing cycles (Stahel, 2013); even in the most advanced recycling processes, there is certain material quality and quantity loss (Cullen, 2017). Moreover, the energy input required for recycling which, to date, may not necessarily sourced from renewables, needs to be considered. In addition, there are some added risks in certain recycling processes, such as in the case of certain chemicals. For smaller waste flows, the environmental costs of transportation to plants where economies of scale can be met outweigh the benefits of recycling (Bilitewski, 2012; Stahel, 2013). As a consequence, recycling is the least environmentally sustainable solution of the three CE principles (Ghisellini et al., 2016). Furthermore, total recyclability may lead to attitudes leading to less material reduction in the first place (Catlin and Wang, 2013), which would entail a risk considering that recycling cycles (with current technologies) are finite and result in gradual loss of energy and materials (Cullen, 2017). Despite this, waste recycling has dominated the CE discourse at the practical level (Stahel, 2013), particularly in Europe (McDowall et al., 2017).

Aiming to address the shortcomings of the $3 \mathrm{R}$ principles and providing a more comprehensive and systemic understanding of the CE (Webster, 2013), the Ellen MacArthur Foundation (2012) proposes three addition principles, as noted by Ghisellini et al. (2016). The first one is appropriate design, whereby, apart from minimising production materials, components are selected and designed based on future reuse or recycling options (Braungart et al., 2007; den Hollander et al., 2017). The second is the reclassification of materials between 'technical' and 'biological' depending on the capacity of the biosphere of carrying them and incorporating them into the natural cycles, the former being destined to reuse of recycle and the latter being accepted as disposal to the environment (Lewandowski, 2016; Webster, 2013). Lastly, renewability puts renewable energy at the centre of the production system, not only due to the finite nature of fossil fuels as a natural resource and the harmful emissions derived from their use, but also as a way to insulate the economy from peaks in prices and limited availability (Ghisellini et al., 2016).

\subsection{Major criticisms of the $C E$}

Despite these efforts to safeguard sustainable performance, the limitations of the CE in contributing to sustainable development have also been highlighted (Geissdoerfer et al., 2017; Murray et al., 2017). During the current period of conceptual development of the CE (Blomsma and Brennan, 2017; Reike et al., 2018), various criticisms and interpretations of the frameworks have started to emerge (see Appendix 1 for a summary table). Particularly, these criticisms address the limitations of current interpretations of the
CE as the framework for a transition to a sustainable economy (Geissdoerfer et al., 2017; Ghisellini et al., 2016) can be categorised in the following points:

- Conceptual fragmentation and lack of paradigmatic strength (Blomsma and Brennan, 2017; Korhonen et al., 2018a, 2018b; Reike et al., 2018).

- Oversimplistic, short-time goals that cause a neglect of thermodynamic limits (Blomsma and Brennan, 2017; Geissdoerfer et al., 2017; Kirchherr et al., 2017; Korhonen et al., 2018b, 2018a; Sauvé et al., 2016).

- Loss of quality in materials over the loops and potential lock-in effects (Ghisellini et al., 2016a; Kirchherr et al., 2017; Korhonen et al., 2018b; Winans et al., 2017).

- Overlook of socio-ethical issues in its development and implementation (Blomsma and Brennan, 2017; Geissdoerfer et al., 2017; Kirchherr et al., 2017; Korhonen et al., 2018b; McDowall et al., 2017; Naustdalslid, 2014; Sauvé et al., 2016; Winans et al., 2017).

The literature has addressed these criticisms in different ways. When it comes to conceptual fragmentation, several authors have aimed to provide a revised, more inclusive definition, while providing a research agenda for the CE (Blomsma and Brennan, 2017; Kirchherr et al., 2017; Korhonen et al., 2018b). Therefore, some of the latest advances in the CE are directed towards the goal of providing model clarity for further research and enhanced implementation in practice.

Regarding the second problem, the consideration of the environmental dimension of sustainability in the long run by the $C E$ is questioned. The environment serves the economy in four different ways (Pearce and Turner, 1992; Perman et al., 2003): as an amenity base, as a life-support system, as a resource base, and as a waste sink. The first two are more related with the relationship of humans with the environment, the amenity-based function representing the environment as a recreational space and source of human joy for its mere existence, and the life-support service providing a home for humanity through various, diverse ecosystems that support difference forms of life. The latter have a more direct impact on the economy, not so much on society development: being a source of materials and energy and the recipient of waste by-products. The four of them are important for the development of the socioeconomic system within the natural system, facilitating human existence.

However, the CE omits the amenity base and life-support functions of the environment, focusing on the resource base and waste sink functions (Zwier et al., 2015). This may lead to other environmental problems not accounted for in the CE (Andersen, 2007), particularly as it comes to human development beyond economic growth, since the environment and the economy have other functions for humanity that go beyond the simplification of a zero-waste economy (Zwier et al., 2015). Regarding the potential short-sightedness of the CE goals and objectives, several advances have been made within the field, aiming to provide a more comprehensive framework that integrates better the relationship between material and energy loops and the long-term outcomes of CE practices (Korhonen et al., 2018a; Reike et al., 2018; Sauvé et al., 2016). These developments highlight the limits of the existing CE frameworks in addressing such topics and provide solutions for operationalisation in practice; however, they do not approach the problem of innovation governance that is inherent to existing practices in the CE. Current practices in the CE are criticized because of its over-simplistic goals that emphasize bottom line approaches over a holistic view of sustainability (Murray et al., 2017), for which current schools of thought have not found a 
solution yet (Reike et al., 2018).

Nevertheless, the major criticism to the CE is that it largely overlooks the social dimension of sustainability (Kirchherr et al., 2017; Murray et al., 2017), which is suggested to be a consequence of its origin in industrial ecology and its alleged analogy with the natural systems (Oh et al., 2016; Sahakian, 2016). In this regard (Moreau et al., 2017), call for applying social and solidarity economy principles to the $\mathrm{CE}$ for a democratization of the economy; hence conveying to the common good regardless of economic profitability (Murray et al., 2017, p. 377). propose revising the concept of a CE to "an economic model wherein planning, resourcing, procurement, production and reprocessing are designed and managed, as both process and output, to maximize ecosystem functioning and human well-being". Beyond the inclusion of social goals in the CE, on a practical level there is an array of social issues that are not covered by CE frameworks, such as ownership, value capture and distribution of waste streams for the recycling industries, or how to involve the public in the design of socially acceptable and desirable environmental solutions. As highlighted by (Winans et al., 2017), the absence of stakeholder engagement is preventing further successful implementation, and there are severe governance issues that fragment CE practices when this should be approached systemically (Korhonen et al., 2018b; Naustdalslid, 2014). Issues like business models or the role of consumers, which would help to clarify ownership and value capture, are only scarcely discussed in the CE literature (Kirchherr et al., 2017; Linder and Williander, 2017). The distribution of value downstream is lost because of the fragmentation between different levels of research - macro, meso and micro - (Korhonen et al., 2018b; Sauvé et al., 2016).

In tackling these two criticisms of the $\mathrm{CE}$, the emerging concept of RRI, which aims to provide an innovation governance framework that integrates socio-ethical considerations in the innovation process, could prove useful. This is so because not only the tackling of social issues is missing from current frameworks, but also the social elements that are required to proceed with wider changes in the socio-technical system. In addition, RRI aims to stimulate the discussion among different stakeholders about the goals of innovation to define what might be socially desirable, ethically acceptable and sustainable results, which might be instrumental to tackle conceptual fragmentation in the development of frameworks for the CE.

\subsection{RRI as a tool for anticipation and reflection in the $C E$}

As previously noted, one of the major criticisms of existing CE frameworks (as identified in the literature) is that they take a shortterm approach to sustainability (Geissdoerfer et al., 2017b). The oversimplification of objectives has, on the one hand, attracted business to the framework, by providing clear guidelines and the promise of economic growth attached to environmental sustainability (Murray et al., 2017; Sauvé et al., 2016). On the other hand, the overlook of thermodynamics (Korhonen et al., 2018a; Winans et al., 2017) in the idea of indefinite recyclability of materials and the need for a systemic shift beyond eco-efficiency practices are also a result of the absence of long-term thinking in many $\mathrm{CE}$ frameworks (Reike et al., 2018). This may lead to unintended consequences (Murray et al., 2017), which would be aggravated by the effect of technological lock-in effects (Korhonen et al., 2018a) For example, Stahel (2013) cites material abuse as an unintended consequence of CE. If a material, for instance natural fibres, is found to be efficiently recyclable, this may lead to a surge in the use of this material. Increasing use of that fibre because of its recyclability may result in increased consumption, overuse of water and energy for production, and loss of biodiversity. To address this problem of unintended consequences, the RRI framework for innovation governance shall be helpful.

One of the main objectives of RRI frameworks is to provide an innovation governance framework that prevents unintended consequences from new innovations (Burget et al., 2017a). In that sense, RRI dimensions as contemplated in the AIRR framework (Stilgoe et al., 2013) - anticipation, inclusiveness, reflection and responsiveness - are developed precisely to tackle this problem. More specifically, anticipation and reflection practices should be useful in overcoming the dilemma that the CE presents (Blok and Lemmens, 2015). This dilemma expresses the difficulty posed by the fact that, at the nascent stage of an innovation, we do not know enough about the implications it may unfold to make clear decisions on its diffusion; while once we know about these implications, it may be too late to make preventative decisions to avoid negative, unintended consequences.

Anticipation is expected to reduce the risks associated with the uncertainty inherent to innovation by examining the social, technical, political and environmental context associated with the innovation. In other words, the goal of anticipation is to understand the possible implications of the innovation in question to ensure its acceptability and social desirability (Stilgoe et al., 2013). Therefore, innovators must develop competences in foresight, engagement and integration in order to understand and govern the impacts of the development of new technologies at different levels (Guston, 2014). Anticipatory measures may include stakeholder consultation to assess whether the use of such material was a good choice in terms of sustainability, considering wider implications. However, the anticipatory dimension of RRI has been challenged, suggesting that such anticipation of the future is speculative and therefore fails to hedge the risks of uncertainty (Groves, 2015; Nordmann, 2014). But, in any case it would certainly be useful in raising awareness of some of the upcoming issues, and certainly in providing CE practices with the depth and systemic thinking that they require to lever a transition to a sustainable system, beyond isolated ecoefficiency measures (Reike et al., 2018).

Uncertainty will always be present in a wider system transition such as the one sustained by the CE but including anticipatory measures would certainly help to address the wider implications of the innovation process. Therefore, RRI could further the role of the $\mathrm{CE}$ in the system transition to sustainability, by providing the tools for innovation governance would help to look at the role of CE innovations as part of the environmental, social and economic system, beyond solving a certain environmental problem at a certain point. In this regard, RRI aims to go beyond the precautionary principle, considering going through with innovation processes after a careful acknowledgement and evaluation of the uncertainties that surround it. Tools for innovation governance such as technology foresight, multi-stakeholder dialogue and orchestration of the innovation processes come together under the RRI umbrella, aiming to create awareness of the values and unintended consequences underlying the innovation.

As it comes to reflexivity, it refers to the consideration of the socio-ethical value of innovation to proceed with it, departing from the traditional amorality of science (Stilgoe et al., 2013). Moreover, innovators are expected to also reflect on how their own value system and bounded rationality affect the development of the innovation (Stilgoe et al., 2013). In that sense, reflexivity in the CE innovation process would help to avoid the technological fix approach and help to provide a positioning of the proposed innovation within the wider systemic shift (Kirchherr et al., 2017). The technological fix approach calls for short term, technology-based solutions for a problem or failure in the socio-technical system, which often creates new lock-in effects, create new problems because of unintended effects on system dynamics, and prevents from finding other holistic solutions. 
Therefore, reflexivity mechanisms should help to incorporate the social aspects of in the system. Reflexivity is concerned with being able to scrutinize the potential consequences of the innovation in question, abandoning views of the amorality of science, and hence conducting a critical assessment of the innovation (Stilgoe et al., 2013). In order to do so, systematized tools like ethical technology assessment offer a way to include reflective processes in innovation (Stilgoe et al., 2013), as well as the as do other practices to promote self-awareness within the individual and the organization - for example, tools for prioritization or acknowledgement of individual or organizational values that might have steered the innovation process in a particular direction (Lubberink et al., 2017). Second-order reflexivity tools, such as code of conducts or moratoriums, might also be effective (Stilgoe et al., 2013). In addition, reflexivity is linked with the dimension of inclusion, since it is suggested it can be enhanced by bringing in stakeholders' value and therefore augmenting the scope of reflexivity to perspectives beyond the innovator's (Taebi et al., 2014; Wickson and Carew, 2014), and in more direct manner, through the involvement of ethicists in the innovation process (Stilgoe et al., 2013). This highlights the value of RRI to strengthen the socio-ethical foundations of the $\mathrm{CE}$, as illustrated in the next section.

\subsection{Supporting the socio-ethical foundations of the CE through RRI}

RRI can also be thought of as a way to integrate social values and concerns into CE practices through the participation of stakeholders in the innovation for the CE process. While the integration of social concerns may not be an issue from the understanding referred in certain disciplines, the $C E$ reviews analysed pinpointed this as a major limitation, since the $C E$ is being conceptualised and operationalised as a tool for system transition to sustainability (Geissdoerfer et al., 2017; McDowall et al., 2017). To that extent, the RRI framework may help to address socio-economic and socioethical issues in the $\mathrm{CE}$, for instance, ownership of the revalued waste streams, or participation of new actors in the circular chain. Inclusion of stakeholders calls for the incorporation of their views on the ethical acceptability and social desirability of the innovation in question. Lack of stakeholder engagement has been signalled as an impeding factor for the success of CE projects (Naustdalslid, 2014; Winans et al., 2017), due to the collaborative and systemic nature of projects, which often requires community involvement and working with other stakeholders across the value chain. Both in theory and practice, CE innovations are often focused on the technological aspects while social aspects of the system - including transdisciplinary and involvement of stakeholders other than the focal actor are not addressed. Therefore, their participation would be leveraged not only in terms of signalling social issues that concern the community, but also to identify how they could be solved. Beyond the technological aspects, most disruptive innovations induce changes of social practices; for instance, detergents that allow for an effective wash in cold water, hence reducing the $\mathrm{CO} 2$ emissions. In order to achieve the environmental gain, they are only effective if the user can break with the idea that the use of hot water will result in cleaner clothes. Hence, many technical innovations are only socio-environmentally fruitful if they are accompanied by a change of behaviour of the user. This is the case of many innovations for circularity; for instance, changes in ownership structures in product-service systems that reduce the emotional value attached to an object. In this case, inclusion of stakeholders by making the innovation process more open and reflective (Long and Blok, 2017) would result not only in awareness of these issues, but also in better decision-making as it comes to social desirability and marketability.

Beyond these contribution to the innovation procedure, inclusion shall strengthen the socio-ethical foundations of the $\mathrm{CE}$. RRI aims to provide an innovation governance framework that helps to reflect societal values, so that the outcomes of the innovation are ethically acceptable, socially desirable and sustainable (Von Schomberg, 2013). Stilgoe et al.'s (2013) inclusion dimension of RRI entails the active engagement of stakeholders in the innovation process in order to incorporate their views on the ethical implications of the innovation and enhance decision-making (Blok et al., 2015a). Current frameworks of RRI call for consultative processes (e.g. multi-stakeholder forums), deeper collaboration beyond consultation could be developed through open or participatory innovation (Stilgoe et al., 2013). In order to assess how successfully stakeholder voices are being heard during the innovation process (Callon et al., 2009), suggest three criteria: intensity (how early stakeholders' voices are incorporated in the process and to what extent attention to them is paid), openness (breadth of stakeholders included) and quality (depth and steadiness of the dialogue). Engaging in inclusion practices in the design of circular systems shall widen the disciplinary constraint that is currently limiting the CE to environmental and economic concerns (Sauvé et al., 2016), taking into consideration the needs of different social groups and integrating their goals in the paradigm shift that the CE ought to be (Kirchherr et al., 2017; Korhonen et al., 2018a), and helping to break the barriers between the micro, meso and macro levels by involving different system actors (Naustdalslid, 2014; Reike et al., 2018).

However, the limitations of inclusion as a way to reflect societal values must be acknowledged. Later reflections on these concepts suggest that they might have competing goals (Papadopoulos and Warin, 2007), inclusion referring mostly to the intensity and openness criteria, and deliberation to the quality criterion, and how stakeholder views become ingrained in the decision making process. An example comes from the use of bio-digestors in the transition to the bio-based economy: the bio-gas producer might see it as a sustainable solution, while there might societal resistance for it being used for decomposing human waste, and at the same time, an environmental NGO might see it a technology that maintains the lock-in to non-renewable, limited stock energy systems. Under a truly inclusive governance of RRI, stakeholders should also be able to negotiate the terms of their participation in the innovation process (Oudheusden, 2014). Therefore, inclusion mechanisms such as stakeholder consultation and participatory innovation should be complemented with anticipatory governance aiming to control for the social and ethical impacts of the CE, such as technology assessment (Oudheusden, 2014). In addition, in the case of businesses, the risk of losing a competitive advantage to information spillovers or lengthy consultation processes might trump the call for transparency and mutual responsiveness of RRI (Blok and Lemmens, 2015). In this case, anticipatory and reflection measures should also be a part of the technology assessment, to ensure that socio-ethical values have been taken into consideration in the process.

In any case, anticipating, reflecting and being inclusive should be reflected in the capacity to make changes to the intended innovation to reflect this societal values (Paredes-Frigolett, 2016). This is the last dimension of the RRI framework developed by Stilgoe et al. (2013): responsiveness; that is, the capacity to adapt and redirect the course of the innovation process under the light of socio-ethical issues raised by stakeholders. Therefore, responsibility goes beyond inclusion, including the need to adjust to answer and adjust to society, while acknowledging the limitations of knowledge that may entail further changes in the future; therefore trying to avoid lock-ins to the greater extent possible (Pellizzoni, 2004). A major criticism of current CE frameworks is the fragmentation between the micro, meso and macro levels 
(Korhonen et al., 2018b; Naustdalslid, 2014), which results in problems of governance and overlook of the social aspects caused by the paradigmatic change of the CE (Kirchherr et al., 2017; Korhonen et al., 2018a). Therefore, to be responsive to these issues and integrate them in the design of circular systems, CE actors may need to increase inter-institutional, multi-level collaboration. However, how to make technological adjustments derived from ethical concerns is challenging in practice, because even if an assessment is made ex ante, there are several issues that will emerge during the innovation process, and newly developed technologies may give rise to issues not considered by the innovator or its stakeholders (Taebi et al., 2014). How to exercise responsiveness and establish priorities of action may also be a challenge in the case of value conflicts (Van de Poel, 2009) and due to the fluidity of social processes that results in a an evolving system of values (Taebi et al., 2014).

Consequently, RRI as a governance framework could provide a solution for some of the major criticisms of the CE; mainly, the prevention of unintended consequences and the inclusion of socioethical aspects in its development and goals. However, the limitations in the concept of RRI itself, which is also under development, call for the common development of certain themes, with RRI providing the socio-ethical grounding at the procedural and outcome level that the $\mathrm{CE}$ is currently lacking. In the following section, we pinpoint some of the challenges that have remained unaddressed by both the CE and RRI literature and propose directions for development of the $\mathrm{CE}$ based on future developments of the RRI frameworks.

\section{Blind spots and research agenda}

One of the main limitations of the application of RRI frameworks for the development of the $\mathrm{CE}$ is that, despite both frameworks being part of ecological modernization, only the $\mathrm{CE}$ has gained attention as source of economic growth and the development of a competitive advantage. At the moment, many businesses are being attracted to the CE because of the benefits that are associated with involvement in it (Kirchherr et al., 2017; Reike et al., 2018). The promise of economic growth coupled with environmental sustainability in the CE discourse makes this framework attractive. In the case of RRI, frameworks have been mostly applied and considered from the perspective of basic research, which constitutes a problem when applied to companies that develop such innovations in a market environment, since it is expected from this companies to fulfil these dimensions while creating economic growth (Lubberink et al., 2017; Stahl et al., 2017). The problems highlighted for RRI in competitive environments - information asymmetries and unbalanced degrees of responsibility (Blok and Lemmens, 2015) may also transfer to a CE context: in the creation of systems favorable to CE, other actors - policy-makers or knowledge providers - are considered, but the weight of responsibility is placed upon businesses as central agents of innovation (Prosman et al., 2017; Stahl et al., 2017), which poses difficulties for the integration of the inclusion dimension of RRI in innovations for circularity.

Such centrality of businesses as actors of the CE - which places economic interest in a dominant position-may hinder the full involvement of other societal actors in the innovation process, since other interests would remain secondary to the economic bottomline. This may prevent their knowledge and innovation potential from entering the solutions for so-called 'grand challenges' through the $\mathrm{CE}$, particularly when stakeholders are seen as a passive actor in the innovation process, as in the dominant techno-economic paradigm (Timmermans and Blok, 2018). There is no consensus in the RRI community about how inclusive deliberation shall be operationalised in practice and the power asymmetries in the governance of deliberative processes may trump real participation and influence of stakeholders (Blok et al., 2015a,b; Oudheusden, 2014). Exploring how other frameworks such as co-design, participatory design or used-led design may contribute to stakeholder engagement in the competitive phase of innovation for the $\mathrm{CE}$ should be helpful in addressing these issues (Baldwin and von Hippel, 2011; Quist and Vergragt, 2006), as well as exploring stakeholder engagement from an ethical point of view (Blok, 2019). Therefore, future research may address this issue, responding to the following question: what can an RRI informed CE learn from frameworks for stakeholder participation in the context of competitive environments?

Although RRI understands innovation as a multi-stakeholder, non-linear process, and the CE requires of the participation of all economic actors (including consumers) to close the materials loop in the economy, responsibilities for implementation mostly lie at the supply side. The nascent literature on business models for the CE links the production and consumption sides, but mostly calls for the producer to steer consumers towards a behaviour that enables the CE (Bocken et al., 2016; Tunn et al., 2019). A future agenda for research should involve the issue of the consumption side in the $C E$, considering the inclusion mechanisms that RRI provides. Some CE scholars tackle the change in consumption patterns through changes in circular business models (Ghisellini et al., 2016); however, there are some systemic obstacles in the consumption side that need to be tackled for further success of $C E$, such as the emotional attachment to ownership, privacy issues derived from pay-per-use models and the creation of a demand for more ethically acceptable or environmentally sustainable products. Demand side has been only marginally explored in the case of these frameworks (Cooper, 2016; Schlaile et al., 2017); however, without demand the promise of economic growth associated to the CE cannot be fulfilled. In this regard, there is a need to develop the responsiveness dimension on the supply side, but also at the demand side, creating fluent communication channels to drive consumer behaviour. Therefore, another question that remains is: in which way can supply and demand side be linked and coordinated for the CE through RRI practices breaking stakeholder divides?

Finally, several complementarities have been identified in the previous section, which call for further integration of CE and RRI practices. After examination, we have observed that RRI could be a powerful tool in the transition to a more reflexive, inclusive and socially oriented CE. If it is so, it would be necessary to coordinate policies, practices and theories to make both frameworks advance together. The conceptual fragmentation of the CE and the early development of RRI make it difficult to propose clear-cut measures in the definition of agendas. However, the techniques covered under the anticipation and reflexivity dimensions of RRI aim to stimulate discussion, which might help to close the gap not only between different understandings and expectations of the $\mathrm{CE}$, but also the role of RRI in its development. Under this light, the next question arises: how can the anticipation and reflexivity dimensions of RRI help to coordinate RRI and CE agendas to identify synergies and lead to a more socially conscious CE?

\section{Conclusion}

This research aims to set the ground for a more-strongly socioethically grounded CE by integrating RRI as an innovation governance framework. Both the CE and RRI are sustained by policy and aim at more sustainable innovations; however, while the first focuses on the environmental issues in industrial production, the latter concentrates on the reflection of social values in innovation. We find that there are two main ways in which RRI could further 
the CE: first, anticipating unexpected consequences and acknowledging systemic limits that are not currently taken into consideration; and second, the integration of socio-ethical issues in the CE, and addressing the social implications of the CE through stakeholder participation. In this regard, RRI frameworks can be very powerful tools in addressing the major limitations in interpretation of how the circular economic system should be developed.

However, some issues like the lack of paradigmatic clarity are still to be further addressed in the literature. Both the RRI and CE conceptual development have not reached maturity, which means that different interpretations of the concepts and frameworks are still in development, particularly as they are applied by new actors - as it is the case of industry. Even through the application of RRI frameworks to the $\mathrm{CE}$, some overlaps - such as the anchoring in the techno-economic- call for an integrative research agenda looking at business model, organizational and social innovation and the consumption side of CE and RRI, aiming to guarantee their success as levers in the system transition to sustainability(see Table 1, 2).

\section{Acknowledgement}

We would like to thank NWO (Dutch Research Council), The Netherlands and Climate KIC for the financial support that enabled research for this paper, under the project number 313-99-319.

\section{Appendix 1}

Table 1

Key sources for RRI and main contributions.

\begin{tabular}{|c|c|c|}
\hline Article & Objective of the paper & Main contributions \\
\hline Voegtlin \& Scherer (2017) & $\begin{array}{l}\text { The paper reflects on the role of deliberation } \\
\text { and responsible innovation in contributing to } \\
\text { addressing grand challenges and Sustainable } \\
\text { Development Goals (SDGs). }\end{array}$ & $\begin{array}{l}\text { The paper reconnects the concept of } \\
\text { responsible innovation to wider grand } \\
\text { challenges, and while it does not address the CE } \\
\text { directly, it links it to the SDGs, showing the } \\
\text { potential of the RRI framework to include socio- } \\
\text { ethical concerns in innovations addressing } \\
\text { sustainability. }\end{array}$ \\
\hline Burget et al. (2017) & $\begin{array}{l}\text { To identify the administrative definitions and } \\
\text { dimensions of RRI developed in the literature } \\
\text { through a systematic literature review. }\end{array}$ & $\begin{array}{l}\text { The paper shows that the RRI literature has } \\
\text { been developed in a fragmented manner, yet it } \\
\text { is possible to identify } 6 \text { dimensions of RRI: the } \\
\text { four identified by Stilgoe et al., plus } \\
\text { sustainability and care }\end{array}$ \\
\hline Stahl et al. (2017) & $\begin{array}{l}\text { It proposes a maturity model of RRI that is } \\
\text { applied to three industries, with the aim of } \\
\text { fostering responsibility in corporate innovation } \\
\text { processes. }\end{array}$ & $\begin{array}{l}\text { It shows that RRI frameworks that are directly } \\
\text { applicable in research cannot be directly } \\
\text { applied in competitive environments and } \\
\text { provides a maturity model based on five stages } \\
\text { (unaware, exploratory, defined, proactive and } \\
\text { strategic). }\end{array}$ \\
\hline Lubberink et al. (2017) & $\begin{array}{l}\text { The paper presents a systematic literature } \\
\text { review of articles in the fields of responsible, } \\
\text { social and sustainable innovation. }\end{array}$ & $\begin{array}{l}\text { The article collects a series of practices that have } \\
\text { been reported as responsible, social and } \\
\text { sustainable innovation and that can be framed } \\
\text { under the anticipation, reflexivity, inclusivity } \\
\text { and responsiveness dimensions in the RRI } \\
\text { framework. It draws lessons for further } \\
\text { development of RRI based on existing practices } \\
\text { (particularly in the business context). }\end{array}$ \\
\hline Blok et al. (2015) & $\begin{array}{l}\text { This chapter examines responsible innovation } \\
\text { in industry and the shortcomings the } \\
\text { framework might have in this environment at } \\
\text { the input, throughput and output stages. }\end{array}$ & $\begin{array}{l}\text { Several shortcomings of the RRI framework in } \\
\text { the business environment are identified; } \\
\text { mainly: information asymmetries, lengthy } \\
\text { time-to-market and unbalanced division of } \\
\text { ultimate responsibility. }\end{array}$ \\
\hline Stilgoe et al. (2013) & $\begin{array}{l}\text { This seminal paper develops the AIRR } \\
\text { framework for responsible innovation, } \\
\text { facilitating its implementation. }\end{array}$ & $\begin{array}{l}\text { Four integrated dimensions of responsible } \\
\text { research and innovation are discussed: } \\
\text { anticipation, reflexivity, inclusion and } \\
\text { responsiveness. Each of these dimensions aids } \\
\text { in developing a transparent, democratic and } \\
\text { inclusive innovation process to achieve the RRI } \\
\text { objectives. }\end{array}$ \\
\hline Von Schomberg (2013) & $\begin{array}{l}\text { This seminal work presents the basis for RRI; } \\
\text { hence addressing the grand challenges for an } \\
\text { ethically acceptable, socially desirable and } \\
\text { sustainable innovation process. }\end{array}$ & $\begin{array}{l}\text { Then paper sets the main tenets of RRI, } \\
\text { discussing its origin and mechanisms and how } \\
\text { it can contribute to the development and } \\
\text { competitive advantage of the European Union. }\end{array}$ \\
\hline
\end{tabular}


Table 2

Key papers, objectives and identified criticisms of the CE.

\begin{tabular}{ll}
\hline Article & Objective of the paper \\
\hline Reike et al. (2018) & Examining the historical conceptual development of the \\
& CE and its implementation to provide conceptual clarity
\end{tabular}
and heuristics for policy and business

Korhonen et al. (2018a)

Korhonen et al. (2018b)

Kirchherr et al. (2017)

McDowall et al. (2017)

Murray et al. (2017)

Geissdoerfer et al. (2017)

et al. (2017)

Blomsma and Brennan (2017)

Ghisellini et al. (2016)
Defining the currently vague concept of the CE from the perspective of sustainability science, and critically analyse the existing understanding

Discussing the definitions of the $\mathrm{CE}$ and provide a research approach for the $\mathrm{CE}$

Conceptualizing the CE to provide a common understanding through the analysis of 114 previous definitions of the $\mathrm{CE}$.

Exploring the different approaches in CE policies in China and Europe

Exploring the concept of the $\mathrm{CE}$ and how it has been operationalised in business and policy

Reviewing the literature on sustainability and the CE to achieve conceptual clarity and the similarities and differences between concepts and practices

Reviewing the history of the CE concept to examine how it is implemented in practice

Positioning the theoretical space of the CE by relating it to the frameworks and practices that it encompasses as an umbrella concept, setting a research agenda based on the theories and practices that the CE entails.

Reviewing the literature and practice on the CE to identify its origins, state-of-the-art and its role in the transition to an environmentally sustainable economy.

Identifying the epistemological and practical problems derived from different disciplinary understandings of environmental science, sustainable development and the $\mathrm{CE}$, trying to find out the obstacles posed for the required transdisciplinary research.
Main identified criticisms of the CE

- The literature on the CE is severely fragmented and consists of two main schools; the reformist and the transformationist schools. The reformist school (which is most prominent particularly in practice) is mostly oriented towards eco-efficiency, does not consider an actual transition to a different economic system and does not contemplate a balance among the economic, environmental and social pillars of sustainability. Six limits to the CE are identified:

- Thermodynamic limits (resource consumption and waste emissions not accounted for)

- System boundary limits (spatial and temporal)

- Physical scale of the economy (rebound effect)

- Path dependencies and lock-ins created to the initial but potentially more inefficient - technologies

- Governance and management of material flows

among institutions and sectors

- Social and cultural definitions of the concept of the CE and the concept of waste

- The literature is fragmented, particularly at the distinction between levels, while the paradigmatic transformation needs to be holistic in nature.

- Practices within the CE have been assessed without indepth discussion or consideration of system boundary limits

- The CE is often presented as a collection of reduce, reuse and recycle practices without taking into consideration the required systemic shift.

- Economic and environmental pillars of sustainability are highlighted, with only few mentions to the social pillar or intergenerational equity.

- The impact of business models or consumers on the transition to a CE is barely addressed.

- Different understanding of practices regarded as CE in China and Europe do not allow for mutual comparison or to extract simple policy lessons

- Neglect of the social dimension of sustainable development, which limits the ability of the framework to integrate ethical considerations.

- Oversimplistic objectives that may lead to unintended consequences

- Simplification of the CE concept to resource input, waste and emission output.

- Lack of integration of the social pillar of sustainability.

- Long-term viability is not part of the discussion (as it is in the case of sustainability).

- Narrow framing and unrealistic promises for business

- Lack of stakeholder engagement, which prevents projects from becoming successful in practice

- Potential risks in certain value chains (e.g. food, plastics)

- Quality of materials over time (limits in recyclability loops)

- Lack of paradigmatic clarity in CE: as an example, there is no clear distinction between recycling, downcycling and cascading.

- Unclear relationship between material flows and the related energy flows.

- Loose relationship with other sustainability concepts and neglection of the social pillar.

- While in China it has been operationalised from the ecological economics approach, as part of a wider plan including social issues, in other areas it has been boiled down to a mature economy waste management plan.

- The CE frameworks often not considered that recyclability of materials is not infinite.

- The final objective of the CE is unclear (as compared with the concept of sustainable development). In fact, ambiguity in objectives can be deliberate as a differentiation from sustainable development.

- Lack of social objectives, with enhancement of the environmental and economic aims. Social objectives are only considered as increasing welfare derived from an improved economic situation.

- The CE framework does not account for the limits of virtuous loops of production. 
Table 2 (continued)

\begin{tabular}{|c|c|c|}
\hline Article & Objective of the paper & Main identified criticisms of the CE \\
\hline Naustdalslid (2014) & $\begin{array}{l}\text { Exploring China's strategy to develop the CE as the } \\
\text { environmental pillar of the 'harmonious society'. }\end{array}$ & $\begin{array}{l}\text { - The CE is presented as a top-down process resulted } \\
\text { from social engineering. } \\
\text { - Lack of civil society participation. } \\
\text { - Lack of appropriate indicators, particularly at the } \\
\text { micro (business) level, because of the top-down } \\
\text { approach. }\end{array}$ \\
\hline
\end{tabular}

\section{References}

Alcott, B., 2005. Jevons' paradox. Ecol. Econ. 54, 9-21. https://doi.org/10.1016/j. ecolecon.2005.03.020.

Andersen, M.S., 2007. An introductory note on the environmental economics of the circular economy. Sustain. Sci. 2, 133-140. https://doi.org/10.1007/s11625-0060013-6.

Andrews, D., 2015. The circular economy, design thinking and education for sustainability ,The circular economy, design thinking and education for sustainability. Local Econ. 30, 305-315. https://doi.org/10.1177/0269094215578226.

Baldwin, C., von Hippel, E., 2011. Modeling a paradigm shift: from producer innovation to user and open collaborative innovation. Organ. Sci. 22, 1399-1417. https://doi.org/10.1287/orsc.1100.0618.

Baxter, W., Aurisicchio, M., Childs, P., 2017. Contaminated interaction: another barrier to circular material flows. J. Ind. Ecol. n/a-n/a https://doi.org/10.1111/jiec. 12612.

Bilitewski, B., 2012. The circular economy and its risks. Waste Manag. 32, 1-2. https://doi.org/10.1016/j.wasman.2011.10.004.

Blok, V., 2019. From participation to interruption: toward an ethics of stakeholder engagement, participation and partnership in corporate social responsibility and responsible innovation. In: von Schomberg, R., Hankins, J. (Eds.), Handbook of Responsible Innovation: a Global Resource. Edward Elgar Publishing.

Blok, V., Lemmens, P., 2015. The emerging concept of responsible innovation. Three reasons why it is questionable and calls for a radical transformation of the concept of innovation. In: Koops, B.-I., Oosterlaken, I., Romijn, H., Swierstra, T., Hoven, J. van den (Eds.), Responsible Innovation 2. Springer International Publishing, pp. 19-35.

Blok, V., Hoffmans, L., Wubben, E.F.M., 2015a. Stakeholder engagement for responsible innovation in the private sector: critical issues and management practices. J. Chain Netw. Sci. 15 (2), 147-164.

Blok, V., Long, T.B., Gaziulusoy, A.I., Ciliz, N., Lozano, R., Huisingh, D., Csutora, M., Boks, C., 2015b. From best practices to bridges for a more sustainable future: advances and challenges in the transition to global sustainable production and consumption. J. Clean. Prod. 108, 19-30. https://doi.org/10.1016/j.jclepro.2015. 04.119.

Blomsma, F., Brennan, G., 2017. The emergence of circular economy: a new framing around prolonging resource productivity. J. Ind. Ecol. n/a-n/a https://doi.org/10. $1111 /$ jiec.12603.

Bocken, N.M.P., Pauw, I., de Bakker, C., Grinten, B. van der, 2016. Product design and business model strategies for a circular economy. J. Ind. Prod. Eng. 33, 308-320. https://doi.org/10.1080/21681015.2016.1172124.

Boulding, K.E., 1966. Environmental Quality in a Growing Economy. Resources for the Future, Washington, D.C.

Braungart, M., McDonough, W., Bollinger, A., 2007. Cradle-to-cradle design: creating healthy emissions - a strategy for eco-effective product and system design. J. Clean. Prod., Approaching zero emissions 15, 1337-1348. https://doi.org/10. 1016/j.jclepro.2006.08.003.

Bryman, A., Bell, E., 2015. Business Research Methods, 4 edition. Oxford University Press, Cambridge, United Kingdom : New York, NY, United States of America.

Burget, M., Bardone, E., Pedaste, M., 2017. Definitions and conceptual dimensions of responsible research and innovation: a literature review. Sci. Eng. Ethics 23, 1-19. https://doi.org/10.1007/s11948-016-9782-1.

Callon, M., Lascoumes, P., Barthe, Y., 2009. Acting in an Uncertain World. MIT Press, Cambridge, MA.

Castellani, V., Sala, S., Mirabella, N., 2015. Beyond the throwaway society: a life cycle-based assessment of the environmental benefit of reuse. Integr. Environ. Assess. Manag. 11, 373-382. https://doi.org/10.1002/ieam.1614.

Catlin, J.R., Wang, Y., 2013. Recycling gone bad: when the option to recycle increases resource consumption. J. Consum. Psychol. 23.

Cooper, T., 2016. Longer Lasting Products: Alternatives to the Throwaway Society. CRC Press.

Cullen, J.M., 2017. Circular economy: theoretical benchmark or perpetual motion machine? J. Ind. Ecol. n/a-n/a https://doi.org/10.1111/jiec.12599.

den Hollander, M.C., Bakker, C.A., Hultink, E.J., 2017. Product design in a circular economy: development of a typology of key concepts and terms. J. Ind. Ecol. n/ a-n/a https://doi.org/10.1111/jiec.12610.

Ellen MacArthur Foundation, 2012. Towards the Circular Economy. Ellen MacArthur Foundation.

Esty, D.C., Porter, M.E., 1998. Industrial ecology and competitiveness. J. Ind. Ecol. 2, 35-43. https://doi.org/10.1162/jiec.1998.2.1.35.
European Commision, 2012. Responsible Research and Innovation. Europe's Ability to Respond to Societal Challenges.

European Commission, 2012a. Towards a Circular Economy: A Zero Waste Programme for Europe, Communication from the Commission to the European Parliament, the Council, the European Economic and Social Committee and the Committee of the Regions.

European Commission, 2012b. Sustainable Growth - for a Resource Efficient Greener and More Competitive Economy [WWW Document]. http://ec.europa. eu/europe2020/europe-2020-in-a-nutshell/priorities/sustainable-growth/index_en.htm. accessed 11.29.16.

Figge, F., Young, W., Barkemeyer, R., 2014. Sufficiency or efficiency to achieve lower resource consumption and emissions? The role of the rebound effect. J. Clean. Prod. 69, 216-224. https://doi.org/10.1016/j.jclepro.2014.01.031.

Flipse, S.M., Sanden, M.C.A. van der, Osseweijer, P., 2013. The why and how of enabling the integration of social and ethical aspects in research and development. Sci. Eng. Ethics 19, 703-725. https://doi.org/10.1007/s11948-0129423-2.

Frosch, R.A., 1992. Industrial ecology: a philosophical introduction. Proc. Natl. Acad. Sci. U.S.A. 89, 800-803.

Geissdoerfer, M., Savaget, P., Bocken, N.M.P., Hultink, E.J., 2017. The Circular Economy - a new sustainability paradigm? J. Clean. Prod. 143, 757-768. https://doi. org/10.1016/j.jclepro.2016.12.048.

Geng, Y., Doberstein, B., 2008. Developing the circular economy in China: challenges and opportunities for achieving "leapfrog development. Int. J. Sustain. Dev. World Ecol. 15, 231-239. https://doi.org/10.3843/SusDev.15.3:6.

Geng, Y., Fu, J., Sarkis, J., Xue, B., 2012. Towards a national circular economy indicator system in China: an evaluation and critical analysis. J. Clean. Prod. 23, 216-224. https://doi.org/10.1016/j.jclepro.2011.07.005.

Genus, A., Iskandarova, M., 2018. Responsible innovation: its institutionalisation and a critique. Technol. Forecast. Soc. Change 128,1-9. https://doi.org/10.1016/j. techfore.2017.09.029.

Ghisellini, P., Cialani, C., Ulgiati, S., 2016. A review on circular economy: the expected transition to a balanced interplay of environmental and economic systems. J. Clean. Prod. 114, 11-32. https://doi.org/10.1016/j.jclepro.2015.09.007.

Gregson, N., Crang, M., Fuller, S., Holmes, H., 2015. Interrogating the circular economy: the moral economy of resource recovery in the EU. Econ. Soc. 44 218-243. https://doi.org/10.1080/03085147.2015.1013353.

Gregson, N., Crang, M., Laws, J., Fleetwood, T., Holmes, H., 2013. Moving up the waste hierarchy: car boot sales, reuse exchange and the challenges of consume culture to waste prevention. Resour. Conserv. Recycl. 77, 97-107. https://doi. org/10.1016/j.resconrec.2013.06.005.

Greyson, J., 2007. An economic instrument for zero waste, economic growth and sustainability. J. Clean. Prod., Approaching zero emissions 15, 1382-1390. https://doi.org/10.1016/j.jclepro.2006.07.019.

Groves, C., 2015. Logic of choice or logic of care? Uncertainty, technological mediation and responsible innovation. Nanoethics Dordr. 9, 321-333. https://doi. org/10.1007/s11569-015-0238-x.

Groves, C., 2009. Future ethics: risk, care and non-reciprocal responsibility. J. Glob. Ethics 5, 17-31. https://doi.org/10.1080/17449620902765286.

Guston, D.H., 2014. Understanding 'anticipatory governance. Soc. Stud. Sci. 44 218-242. https://doi.org/10.1177/0306312713508669.

Hukkinen, J., 2001. Eco-efficiency as abandonment of nature. Ecol. Econ. 38 311-315. https://doi.org/10.1016/S0921-8009(01)00217-8.

Jay, J., Gerand, M., 2015. Accelerating the theory and practice of sustainabilityoriented innovation. In: Mit Sloan Sch. Work. Pap. 5148-15.

Kirchherr, J., Reike, D., Hekkert, M., 2017. Conceptualizing the circular economy: an analysis of 114 definitions. Resour. Conserv. Recycl. 127, 221-232. https://doi. org/10.1016/j.resconrec.2017.09.005.

Korhonen, J., Honkasalo, A., Seppälä, J., 2018a. Circular economy: the concept and its limitations. Ecol. Econ. 143, 37-46. https://doi.org/10.1016/j.ecolecon.2017.06 041.

Korhonen, J., Nuur, C., Feldmann, A., Birkie, S.E., 2018b. Circular economy as an essentially contested concept. J. Clean. Prod. 175, 544-552. https://doi.org/10. 1016/j.jclepro.2017.12.111.

Korhonen, J., Seager, T.P., 2008. Beyond eco-efficiency: a resilience perspective. Bus. Strateg. Environ. 17, 411-419. https://doi.org/10.1002/bse.635.

Lacy, P., Rutqvist, J., 2016. Waste to Wealth: the Circular Economy Advantage. Springer.

Lewandowski, M., 2016. Designing the business models for circular economy-towards the conceptual framework. Sustainability 8, 43. https://doi.org/10.3390/ su8010043.

Lieder, M., Rashid, A., 2016. Towards circular economy implementation: a 
comprehensive review in context of manufacturing industry. J. Clean. Prod. 115, 36-51. https://doi.org/10.1016/j.jclepro.2015.12.042.

Linder, M., Williander, M., 2017. Circular business model innovation: inherent uncertainties. Bus. Strateg. Environ. 26, 182-196. https://doi.org/10.1002/bse.1906.

Long, T.B., Blok, V., 2017. Integrating the Management of Socio-Ethical Factors into Commercial Innovation: towards a Concept of Open Innovation 2.0.

Lubberink, R., Blok, V., Ophem, J. van, Omta, O., 2017. A framework for responsible innovation in the business context: lessons from responsible-, social- and sustainable innovation. In: Responsible Innovation 3. Springer, Cham, pp. 181-207. https://doi.org/10.1007/978-3-319-64834-7_11.

Macnaghten, P., Owen, R., Stilgoe, J., Wynne, B., Azevedo, A., Campos, A. de Chilvers, J., Dagnino, R., Giulio, G. di, Frow, E., Garvey, B., Groves, C., Hartley, S., Knobel, M. Kobayashi, E., Lehtonen, M. Lezaun, J., Mello, L, Monteiro, M. Costa, J.P. da, Rigolin, C., Rondani, B., Staykova, M., Taddei, R., Till, C., Tyfield, D., Wilford, S., Velho, L., 2014. Responsible innovation across borders: tensions, paradoxes and possibilities. J. Responsible Innov. 1, 191-199. https://doi.org/10. 1080/23299460.2014.922249.

Madelin, R., 2016. Opportunity now: europe's mission to innovate. EPSC Strateg. Notes 15.

Mathews, J.A., Tan, H., 2011. Progress toward a circular economy in China. J. Ind. Ecol. 15, 435-457. https://doi.org/10.1111/j.1530-9290.2011.00332.x.

McDonough, W., Braungart, M., 2003. Cradle to Cradle: Remaking the Way We Make Things, Edición: 1. Macmillan USA, New York.

McDowall, W., Geng, Y., Huang, B., Barteková, E., Bleischwitz, R., Türkeli, S., Kemp, R., Doménech, T., 2017. Circular economy policies in China and Europe. J. Ind. Ecol. n/a-n/a https://doi.org/10.1111/jiec.12597.

Moreau, V., Sahakian, M., van Griethuysen, P., Vuille, F., 2017. Coming full circle: why social and institutional dimensions matter for the circular economy. J. Ind. Ecol. n/a-n/a https://doi.org/10.1111/jiec.12598.

Murray, A., Skene, K., Haynes, K., 2017. The circular economy: an interdisciplinary exploration of the concept and application in a global context. J. Bus. Ethics 140 369-380. https://doi.org/10.1007/s10551-015-2693-2.

Naustdalslid, J., 2014. Circular economy in China - the environmental dimension of the harmonious society. Int. J. Sustain. Dev. World Ecol. 21, 303-313. https://doi. org/10.1080/13504509.2014.914599.

Nordmann, A., 2014. Responsible innovation, the art and craft of anticipation. J. Responsible Innov. 1, 87-98. https://doi.org/10.1080/23299460.2014.882064.

Oh, D.-S., Phillips, F., Park, S., Lee, E., 2016. Innovation ecosystems: a critical examination. Technovation 54, 1-6. https://doi.org/10.1016/j.technovation.2016. 02.004 .

Oudheusden, M. van, 2014. Where are the politics in responsible innovation? European governance, technology assessments, and beyond. J. Responsible Innov. 1, 67-86. https://doi.org/10.1080/23299460.2014.882097.

Owen, R., Macnaghten, P., Stilgoe, J., 2012. Responsible research and innovation: from science in society to science for society, with society. Sci. Publ. Pol. 39, 751-760. https://doi.org/10.1093/scipol/scs093.

Papadopoulos, Y., Warin, P., 2007. Are innovative, participatory and deliberative procedures in policy making democratic and effective? Eur. J. Political Res. 46, 445-472. https://doi.org/10.1111/j.1475-6765.2007.00696.x.

Paredes-Frigolett, H., 2016. Modeling the effect of responsible research and innovation in quadruple helix innovation systems. Technol. Forecast. Soc. Change 110, 126-133. https://doi.org/10.1016/j.techfore.2015.11.001.

Pauli, G.A., 2010. The Blue Economy: 10 Years, 100 Innovations, 100 Million Jobs. Paradigm Publications, Taos, NM.

Pearce, D., Turner, R.K., 1992. Packaging waste and the polluter pays principle: taxation solution. J. Environ. Plan. Manag. 35, 5-15. https://doi.org/10.1080/ 09640569208711905.

Pellizzoni, L., 2004. Responsibility and environmental governance. Environ. Pol. 13 541-565. https://doi.org/10.1080/0964401042000229034.

Perman, R., Ma, Y., McGilvray, J., Common, M., 2003. Natural Resource and Environmental Economics. Pearson Education, Harlow.

Prosman, E.J., Wæhrens, B.V., Liotta, G., 2017. Closing global material loops: initial insights into firm-level challenges. J. Ind. Ecol. n/a-n/a https://doi.org/10.1111/ jiec.12535.

Quist, J., Vergragt, P., 2006. Past and future of backcasting: the shift to stakeholder participation and a proposal for a methodological framework. Futures 38 1027-1045. https://doi.org/10.1016/j.futures.2006.02.010.

Reber, B., 2017. RRI as the inheritor of deliberative democracy and the precautionary principle. J. Responsible Innov. 0, 1-27. https://doi.org/10.1080/23299460.2017. 1331097.

Reike, D., Vermeulen, W.J.V., Witjes, S., 2018. The circular economy: new or refurbished as CE 3.0? - exploring controversies in the conceptualization of the circular economy through a focus on history and resource value retention options. Resour. Conserv. Recycl., Sustain. Resour. Manag. Circ. Econ. 135, 246-264. https://doi.org/10.1016/j.resconrec.2017.08.027.

Ruggiu, D., 2015. Anchoring european governance: two versions of responsible research and innovation and EU fundamental rights as "normative anchor points. Nanoethics 9, 217-235. https://doi.org/10.1007/s11569-015-0240-3.

Sahakian, M., 2016. The social and solidarity economy: why is it relevant to industrial ecology?. In: Taking Stock of Industrial Ecology. Springer, Cham, pp. 205-227. https://doi.org/10.1007/978-3-319-20571-7_10.

Saille, S. de, 2015. Innovating innovation policy: the emergence of 'responsible research and innovation. J. Responsible Innov. 2, 152-168. https://doi.org/10. 1080/23299460.2015.1045280.
Sakai, S., Yoshida, H., Hirai, Y., Asari, M., Takigami, H., Takahashi, S., Tomoda, K., Peeler, M.V., Wejchert, J., Schmid-Unterseh, T., Douvan, A.R., Hathaway, R., Hylander, L.D., Fischer, C., Oh, G.J., Jinhui, L., Chi, N.K., 2011. International comparative study of $3 \mathrm{R}$ and waste management policy developments. J. Mater. Cycles Waste Manag. 13, 86-102. https://doi.org/10.1007/s10163-011-0009-x.

Sauvé, S., Bernard, S., Sloan, P., 2016. Environmental sciences, sustainable development and circular economy: alternative concepts for trans-disciplinary research. Environ. Dev. 17, 48-56. https://doi.org/10.1016/j.envdev.2015.09.002.

Schlaile, M.P., Mueller, M., Schramm, M., Pyka, A., 2017. Evolutionary economics, responsible innovation and demand: making a case for the role of consumers. Philos. Manag. 1-33. https://doi.org/10.1007/s40926-017-0054-1.

Schoenberger, H., 2009. Integrated pollution prevention and control in large industrial installations on the basis of best available techniques - the Sevilla Process. J. Clean. Prod. 17, 1526-1529. https://doi.org/10.1016/j.jclepro.2009.06. 002.

Schot, J., Rip, A., 1997. The past and future of constructive technology assessment Technol. Forecast. Soc. Change, Technol. Assess.: The End of OTA 54, 251-268. https://doi.org/10.1016/S0040-1625(96)00180-1.

Schumpeter, J.A., 1912. Theorie der wirtschaftlichen Entwicklung. Duncker \& Humblot.

Sousa-Zomer, T.T., Magalhães, L., Zancul, E., Campos, L.M.S., Cauchick-Miguel, P.A., 2018. Cleaner production as an antecedent for circular economy paradigm shift at the micro-level: evidence from a home appliance manufacturer. J. Clean. Prod. 185, 740-748. https://doi.org/10.1016/j.jclepro.2018.03.006.

Stahel, W.R., 2016. The circular economy. Nat. News 531, 435. https://doi.org/10. $1038 / 531435 a$

Stahel, W.R., 2013. Policy for material efficiency-sustainable taxation as a departure from the throwaway society. Phil. Trans Roy Soc. A 371, 20110567. https:// doi.org/10.1098/rsta.2011.0567.

Stahel, W.R., Reday, G., 1981. Jobs for Tomorrow, the Potential for Substituting Manpower for Energy. Vantage Press, NY.

Stahl, B.C., Obach, M., Yaghmaei, E., Ikonen, V., Chatfield, K., Brem, A., 2017. The responsible research and innovation (RRI) maturity model: linking theory and practice. Sustainability 9, 1036. https://doi.org/10.3390/su9061036.

Stilgoe, J., Owen, R., Macnaghten, P., 2013. Developing a framework for responsible innovation. Res. Pol. 42, 1568-1580. https://doi.org/10.1016/j.respol.2013.05. 008.

Taebi, B., Correljé, A., Cuppen, E., Dignum, M., Pesch, U., 2014. Responsible innovation as an endorsement of public values: the need for interdisciplinary research. J. Responsible Innov. 1, 118-124. https://doi.org/10.1080/23299460. 2014.882072.

Thomas, V.M., 1997. Industrial ecology: towards closing the materials cycle. J. Ind. Ecol. 1, 149-151. https://doi.org/10.1162/jiec.1997.1.2.149.

Timmermans, J., Blok, V., 2018. A critical hermeneutic reflection on the paradigmlevel assumptions underlying responsible innovation. Synthese. https://doi. org/10.1007/s11229-018-1839-z.

Tukker, A., 2015. Product services for a resource-efficient and circular economy - a review. J. Clean. Prod., Special Volume: Why have 'Sustainable Product-Service Systems' not been widely implemented? 97, 76-91. https://doi.org/10.1016/j. jclepro.2013.11.049.

Tunn, V.S.C., Bocken, N.M.P., van den Hende, E.A., Schoormans, J.P.L., 2019. Business models for sustainable consumption in the circular economy: an expert study. J. Clean. Prod. 212, 324-333. https://doi.org/10.1016/j.jclepro.2018.11.290.

Van de Poel, I.R., 2009. Values in engineering design. In: Philosophy of Technology and Engineering Sciences. Elsevier, Amsterdam, pp. 973-1006.

Voegtlin, C., Scherer, A.G., 2017. Responsible innovation and the innovation of responsibility: governing sustainable development in a globalized world. J. Bus. Ethics 143, 227-243. https://doi.org/10.1007/s10551-015-2769-z.

Von Schomberg, R., 2013. A vision of responsible research and innovation. In: Responsible Innovation. John Wiley, London.

Von Schomberg, R., 2012. The quest for the "right" impacts of science and technology. An outlook towards a framework for responsible research and innovation. In: Les Nanotechnologies: Vers Un Changement D'échelle Éthique? E.M.E. \& InterCommunications, Bruxelles, pp. 269-287.

Webster, K., 2013. What might we say about a circular economy? Some temptations to avoid if possible. World Futur. 69, 542-554. https://doi.org/10.1080/ 02604027.2013.835977.

Wickson, F., Carew, A.L., 2014. Quality criteria and indicators for responsible research and innovation: learning from transdisciplinarity. J. Responsible Innov. 1, 254-273. https://doi.org/10.1080/23299460.2014.963004.

Winans, K., Kendall, A., Deng, H., 2017. The history and current applications of the circular economy concept. Renew. Sustain. Energy Rev. 68, 825-833. https:// doi.org/10.1016/j.rser.2016.09.123.

Wohlin, C., 2014. Guidelines for snowballing in systematic literature review studies and a replication in software engineering. In: Proceedings of the 18th International Conference on Evaluation and Assessment in Software Engineering. Presented at the EASE 2014. ACM, London, UK, pp. 38-48.

Zwart, H., Landeweerd, L., van Rooij, A., 2014. Adapt or perish? Assessing the recent shift in the European research funding arena from 'ELSA' to 'RRI. Life Sci. Soc. Policy 10. https://doi.org/10.1186/s40504-014-0011-x.

Zwier, J., Blok, V., Lemmens, P., Geerts, R.-J., 2015. The ideal of a zero-waste humanity: philosophical reflections on the demand for a bio-based economy. J. Agric. Environ. Ethics 28, 353-374. https://doi.org/10.1007/s10806-015-9538y. 